\title{
Diffuse Follicular Lymphoma
}

National Cancer Institute

\section{Source}

National Cancer Institute. Diffuse Follicular Lymphoma. NCI Thesaurus. Code C7264.

A lymphoma with the morphologic and immunophenotypic features of a follicular lymphoma that shows entirely a diffuse pattern. It is usually seen in small biopsy specimens and most probably represents a diffuse area of a follicular lymphoma. 